\title{
ORIGINAL ARTICLE Reliability and validity of three functional tests in ambulatory patients with spinal cord injury
}

\author{
P Poncumhak $^{1,2}$, J Saengsuwan ${ }^{1,3}$, W Kamruecha ${ }^{1,4}$ and S Amatachaya ${ }^{1,4}$
}

\begin{abstract}
Study design: A cross-sectional study.
Objectives: To investigate reliability, discriminative ability and concurrent validity of three functional tests (including the 10-meter walk test (1OMWT), timed up and go test (TUGT) and five times sit-to-stand test (FTSST)) using the Functional Independence Measure Locomotor (FIM-L) scores as a standard criterion.

Setting: A tertiary rehabilitation center, Thailand.

Methods: Subjects were 66 patients with spinal cord injury (SCl), who were able to walk at least 50 m unassisted with or without a walking device (FIM-L scores 6-7). They were tested for functional ability using the 1OMWT, TUGT and FTSST. Sixteen subjects also assessed the ability using three assessors to evaluate the inter-tester reliability of the tools.

Results: The three functional tests demonstrated excellent inter-tester reliability (intraclass correlation coefficient $(3,3)=$ 0.997-1.00) and could clearly distinguish between subjects who walked with and without a walking device. In addition, the tests showed significant correlation with walking categories or FIM-L scores $\left(r_{\mathrm{pb}}=0.778,-0.692\right.$ and -0.595 for the $10 \mathrm{MWT}$, TUGT and FTSST, respectively, $P<0.001$ ).

Conclusion: The findings support reliability and validity of the 10MWT, TUGT and FTSST to assess levels of independences in ambulatory subjects with $\mathrm{SCl}$.
\end{abstract}

Spinal Cord (2013) 51, 214-217; doi:10.1038/sc.2012.126; published online 13 November 2012

Keywords: spinal cord injury; walking; balance; muscle strength; rehabilitation

\section{INTRODUCTION}

More than $80 \%$ of patients with incomplete spinal cord injury (SCI) can regain ambulatory capability. ${ }^{1,2}$ However, their walking ability is likely to be limited to within the house, for a short distance or with the support of an assistive/walking device.,4 Clinically, walking devices are commonly prescribed to compensate for the reduction of walking ability, balance control and lower extremity muscle strength (LEMS) in order to promote a level of independence for the patients. ${ }^{4-6}$ However, long lasting use of a walking device poses negative impacts on the patients such as induced abnormal posture and musculoskeletal pain, required high attention demand and energy expenditure, and increased risk of fall. ${ }^{7,8}$ Mahoney et al. ${ }^{9}$ also reported that the use of a walking device was associated with an increased risk of functional decline in the elderly. Therefore, the incorporation of a valid and reliable objective tool relating to the requirements of a walking device is important to monitor the level of independence of patients.

The 10-meter walk test (10MWT) reflects walking speed that relates to motor function and overall quality of walking. ${ }^{10}$ The timed up and go test (TUGT) measures balance control during upright and walking activities. ${ }^{11}$ The five times sit-to-stand test (FTSST) correlates with LEMS, multiple sensorimotor processes, balance control and psychological status. ${ }^{12-14}$ These tests are practical and measure levels of abilities relating to the requirement of walking devices. The use of these tests may clearly quantify functional alteration and benefit monitoring process for these individuals.

The FTSST has been extensively applied to measure LEMS and balance control in many groups of subjects. ${ }^{12-14}$ However, there is no existing literature on the use of this test in patients with SCI. For the 10MWT and TUGT, van Hedel et al. ${ }^{15}$ report that these tools are valid and reliable to assess walking ability in patients with SCI. However, the study utilized the Walking Index for Spinal Cord Injury II (WISCI II) as a standard criterion for subject classification. ${ }^{15}$ The tool incorporates 0-20 gradations according to physical assistance and devices required for walking $10 \mathrm{~m} .{ }^{16}$ Such ranking scores are based on impairment improvement rather than independent function, thus focus on capacity not disability or burden of care. ${ }^{17}$ van Hedel et al. ${ }^{15}$ also questioned whether the ranking categories in the WISCI II are optimal because the crucial goal in patients with SCI is to achieve independent walking even if orthoses or other walking aids are used. For example, category 16 (ambulates with two crutches, no braces and no physical assistance, $10 \mathrm{~m})$ is scored poorer than category 17 (ambulated with no devices, no braces and physical assistance of one person, $10 \mathrm{~m}) .{ }^{18}$ The researchers indicate that it may be better to score independent walking as being superior to the requirement of external assistance. ${ }^{15}$ This may suggest the use of criteria from other disability scales to classify levels of independence of patients with SCI such as the Functional Independent Measurement Locomotor (FIM-L)

${ }^{1}$ Improvement of Physical Performance and Quality of Life (IPQ) Research Group, Khon Kaen University, Khon Kaen, Thailand; ${ }^{2}$ Department of Physical Therapy, School of Allied Health Sciences, University of Phayao, Phayao, Thailand; ${ }^{3}$ Faculty of Public Health, Khon Kaen University, Khon Kaen, Thailand and ${ }^{4}$ School of Physical Therapy, Faculty of Associated Medical Sciences, Khon Kaen University, Khon Kaen, Thailand

Correspondence: Associate Professor Dr S Amatachaya, School of Physical Therapy, Faculty of Associated Medical Sciences, Khon Kaen University, Khon Kaen 40002, Thailand. E-mail: samata@kku.ac.th

Received 24 April 2012; revised 17 September 2012; accepted 20 September 2012; published online 13 November 2012 
scores, which by definition measure levels of functioning of patients in different environments that accurately reflect burden of care. ${ }^{10,19}$ Thus this study evaluated the reliability and validity (in terms of discriminative ability and concurrent validity) of the 10MWT, TUGT and FTSST using the FIM-L scores as a standard criterion. Findings of the study would direct the use of these tests to quantify and monitor the levels of independence of the patients.

\section{MATERIALS AND METHODS}

\section{Subjects and Setting}

The study was executed during April 2011-May 2012 in a tertiary rehabilitation center, Thailand. Seventy-nine independent ambulatory patients with incomplete SCI from either traumatic or non-traumatic causes agreed to participate in the study. The inclusion criteria were ability to stand up from a chair or bed independently without the use of hands and to walk independently with or without a walking device at least $50 \mathrm{~m}$ continuously (FIM-L scores 6-7). Thirteen patients were excluded (Figure 1); thus 66 patients completed the validity test and 16 of them also participated in the inter-tester reliability test. Figure 1 shows subject participation flowchart. Table 1 presents baseline demographics and SCI characteristics of subjects. Eligible subjects are needed to sign an informed consent document approved by the local ethics committee prior to taking part in this study.

\section{Experimental procedures}

Subjects participated in the study for two consecutive days. On the first day, they were interviewed and assessed for their baseline demographics, SCI characteristics and baseline walking ability (ability of walking at least $50 \mathrm{~m}$ continuously with or without a walking device). Then, subjects were arranged into two groups according to the requirements of a walking device (FIM-L scores). Subjects with FIM-L 6 were those who could walk independently at least $50 \mathrm{~m}$ with the use of a walking device, and FIM-L 7 referred to those who were able to walk independently at least $50 \mathrm{~m}$ without using any assistive devices. ${ }^{10}$ On the second day, subjects were tested for their functional abilities using the 10MWT, TUGT and FTSST in a random order using the Latin square to minimize carrying-over effects due to sequences of the tests that might occur such as fatigue and learning effects. Each test was performed over three trials, and the average performance of the three trials was used for data analysis. In order to warrant safety, subjects had to wear a safety belt around

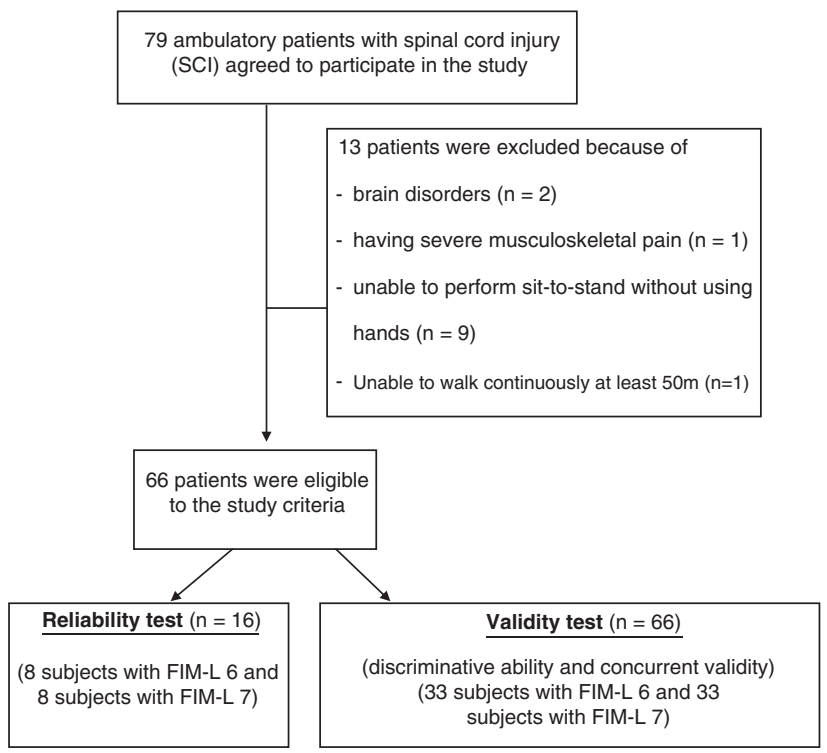

Figure 1 Subject participation. FIM-L 6 , subjects walked $\geqslant 50 \mathrm{~m}$ with the use of walking device; FIM-L 7, subjects walked $\geqslant 50 \mathrm{~m}$ without the use of walking device. their waist with a physiotherapist walking or being at the side of the subject throughout the tests. Details of the tests are as follows:

10MWT. Subjects walked with a preferred walking device at a comfortable pace along a $10-\mathrm{m}$ walkway without any break to the end point. In order to minimize acceleration and deceleration effects, the test recorded the time required to cover the middle $4 \mathrm{~m}$ of the walkway. ${ }^{20}$ Then the time required over the $4 \mathrm{~m}$ was converted to walking speed.

TUGT. Subjects stood up from an armrest chair, walked around a traffic cone that was located $3 \mathrm{~m}$ away from the chair, and returned to sit down on the chair at a maximum and safe speed. During the test, subjects were able to use a preferred walking device. The test recorded the time taken from the word 'Go' until the subject's back was against the backrest of the chair. ${ }^{11}$

FTSST. Subjects sat on an armless chair with their arms on the sides, back upright, hip flexion 90 degrees and feet flat on the floor at $10 \mathrm{~cm}$ behind the knees. Then they were instructed to stand up with the hips and knees in full extension, and sit down five times as quickly and safely as they could without using the arms. This test recorded the time from the command 'Go' until the subject's back touched the backrest of the chair on the fifth repetition. ${ }^{12,21}$

Reliability test. The study investigated inter-tester reliability of the tools in 16 subjects with FIM-L 6 and 7 (eight subjects/group) using three physiotherapists who had different clinical experience (range 2-5 years). Prior to participation, the assessors were trained to use the same and standard methods. Then they simultaneously evaluated ability of each subject using the 10MWT, TUGT and FTSST in a random order. Each test was performed three trials with a period of sufficient rest between the trials. The average findings for the three trials of each assessor were used to analyze the intertester reliability of the tools.

\section{Statistical analyses}

Data were analyzed using the SPSS for Windows program (SPSS Statistics 17, IBM Corporation, 1 New Orchard Road Armonk, NY, USA, serial number: 5068054). Descriptive statistics were applied to explain baseline characteristics and findings of the study. The intraclass correlation coefficients $(3,3)$ were utilized to determine the inter-tester reliability of the tests. The independent samples $t$-test was used to compare the findings of continuous data between subjects who walked with (FIM-L 6) and without walking devices (FIM-L 7). The point biserial correlation coefficient $\left(r_{\mathrm{pb}}\right)$ was applied to determine the levels of correlation between findings of functional tests and walking categories (FIM-L scores). The level of significance was set at $P<0.05$.

Table 1 Baseline characteristics of the subjects

\begin{tabular}{|c|c|c|c|}
\hline \multirow[t]{2}{*}{ Variables } & \multicolumn{2}{|c|}{ Validity tests } & \multirow{2}{*}{$\begin{array}{c}\text { Reliability test } \\
(n=16)\end{array}$} \\
\hline & $\begin{array}{l}F I M-L 6 \\
(\mathrm{n}=33)\end{array}$ & $\begin{array}{l}F I M-L 7 \\
(n=33)\end{array}$ & \\
\hline Age (mean \pm s.d.) (years) ${ }^{a}$ & $50.9 \pm 13.4$ & $50.2 \pm 9.5$ & $50.8 \pm 10.3$ \\
\hline $\begin{array}{l}\text { Post-injury time (mean } \pm \text { s.d.) } \\
\text { (months) })^{a}\end{array}$ & $59.5 \pm 85.8$ & $44 \pm 64.5$ & $30.6 \pm 19.9$ \\
\hline Genders: males/females $(n)$ & $22 / 11$ & $24 / 9$ & $11 / 5$ \\
\hline $\begin{array}{l}\text { Causes: (non-traumatic/trau- } \\
\text { matic), } n\end{array}$ & $20 / 13$ & $21 / 12$ & $8 / 8$ \\
\hline Severity of injury (AIS C/D), $n$ & $9 / 24$ & $1 / 32$ & $2 / 15$ \\
\hline $\begin{array}{l}\text { Levels of injury (tetraplegia/ } \\
\text { paraplegia), } n\end{array}$ & $9 / 24$ & $13 / 20$ & $6 / 10$ \\
\hline
\end{tabular}

Abbreviations: AIS, American Spinal Injury Association Impairment Scale; FIM-L 6, subjects walked $\geqslant 50 \mathrm{~m}$ with the use of walking devices; FIM-L 7 , subjects walked $\geqslant 50 \mathrm{~m}$ without the walked $\geqslant 50 \mathrm{~m}$,

The comparison between subjects with FIM-L 6 and FIM-L 7 using the independent sample $t$-test was not significant differences $(P>0.05)$. 
Table 2 Inter-tester reliabilities of the three functional tests

\begin{tabular}{|c|c|c|c|c|}
\hline \multirow[t]{2}{*}{ Functional tests } & \multicolumn{2}{|c|}{$F I M-L 6(n=8)$} & \multicolumn{2}{|c|}{$F I M-L 7(n=8)$} \\
\hline & ICCs & $95 \% \mathrm{Cl}$ & ICCs & $95 \% \mathrm{Cl}$ \\
\hline 10-Meter walk test* & 0.999 & $0.996-1.000$ & 1.000 & $0.999-1.000$ \\
\hline Timed up and go test* & 0.999 & $0.999-1.000$ & 1.000 & $0.999-1.000$ \\
\hline Five times sit-to-stand test* & 0.999 & $0.997-1.000$ & 0.997 & $0.991-0.999$ \\
\hline
\end{tabular}

Abbreviations: $\mathrm{Cl}$, confidence interval; FIM-L 6 , subjects walked $\geqslant 50 \mathrm{~m}$ with the use of walking devices; FIM-L 7 , subjects walked $\geqslant 50 \mathrm{~m}$ without the use of walking devices.

* $P$-value from the Intraclass correlation coefficients $($ ICC) $(3,3)<0.001$

Table 3 Functional abilities in subjects with FIM-L 6 and FIM-L 7

\begin{tabular}{lcr}
\hline Functional tests & FIM- $L 6(\mathrm{n}=33)$ & FIM- $L 7(\mathrm{n}=33)$ \\
\hline 10-Meter walk test $\left(\mathrm{m} \mathrm{s}^{-1}\right)^{*}$ & $0.41 \pm 0.20$ & $0.92 \pm 0.22$ \\
Timed up and go test $(\mathrm{s})^{*}$ & $30.74 \pm 13.57$ & $11.95 \pm 3.78$ \\
Five times sit-to-stand test (s)* & $18.44 \pm 6.16$ & $11.01 \pm 3.72$ \\
\hline
\end{tabular}

Abbreviations: FIM-L 6 , subjects walked $\geqslant 50 \mathrm{~m}$ with the use of walking devices; FIM-L 7 , subjects walked $\geqslant 50 \mathrm{~m}$ without the use of walking devices.

Data were presented using mean \pm s.d.

$* P$-value from the independent samples $t$-test $<0.001$.

\section{RESULTS}

The three functional tests demonstrated excellent inter-tester reliability in both subjects who walked with and without a walking device (intraclass correlation coefficients $=0.997-1.00$, Table 2). Subjects with FIM-L 7 walked at a significantly greater speed and required significantly less time to complete the TUGT and FTSST than those with FIM-L $6(P<0.001$, Table 3$)$. These functional tests significantly correlated with the levels of walking ability as classified using the FIM-L scores $(P<0.001)$. Among the three tests, the 10MWT showed the highest correlation with the FIM-L scores $\left(r_{\mathrm{pb}}=0.778\right)$, followed by the TUGT $\left(r_{\mathrm{pb}}=-0.692\right)$ and FTSST $\left(r_{\mathrm{pb}}=-0.595\right)$, respectively.

\section{DISCUSSION}

Walking devices are often required to promote balance control and reduce lower-limb loading by allowing stabilizing reaction forces to be generated at the upper extremities so that the patients can maintain balance and move more independently. ${ }^{6}$ However, walking with a walking device needs considerable attention, neuromotor, musculoskeletal, physiologic and metabolic demands that affect walking speed and long-term ability. ${ }^{4,6}$ The 10MWT, TUGT and FTSST quantify different aspects of functional abilities relating to the requirement of walking devices. Thus they could clearly distinguish between subjects who walk with and without a walking device (Table 3). The 10MWT reflects walking speed that associates with motor function, walking endurance and overall quality of gait. ${ }^{10}$ The TUGT requires subjects to perform sequential locomotor tasks that incorporate sitting-to-standing, walking and turning activities. Results of the test correlate with levels of functional mobility, balance and postural control, walking ability and the risk of falls. ${ }^{11}$ The FTSST is a sensitive and responsive tool to assess proximal muscle strength of the lower extremities, sensorimotor integration and balance control, which are vital for the capability to wean off a walking device. ${ }^{4,6,8,12-14}$ These tests are also reliable and significantly correlated with walking categories (Table 2). Higher levels of correlation of the 10MWT and TUGT may be that these tests incorporate more complex tasks relating to walking than the FTSST.

Previously, van Hedel et al. ${ }^{15}$ reported that the 10MWT, TUGT and 6-minute walk test (6MinWT) correlated well with the levels of walking ability as determined using the WISCI II scores. However, in subjects with severe walking disability (WISCI II scores $\leqslant 10$ ), the correlation was positively low with the TUGT $(P=0.16)$, and negatively low with the 10MWT and 6MinWT $(P=-0.24$ and -0.22 , respectively). ${ }^{15}$ This infers that improved walking ability, as indicated by the WISCI II scores, relates to the increased time required to complete the TUGT, and decreased walking speed and distance covered in $6 \mathrm{~min}$. However, when the researchers divided subjects into dependent and independent walkers, the correlation was returned as expected. ${ }^{15}$ Therefore, the researchers suggest the classification of patients with SCI in terms of levels of independent walking rather than the requirement of external assistance. This study employed standard criteria from the FIM-L scores (FIM-L 6 and 7) in order to classify subjects into independent walkers and modified independent walkers, irrespective to types of a walking device used. Although the FIM-L had less sensitivity to detect changes than the WISCI II, the study applied the FIM-L as a standard criterion to categorize walking ability of the subjects without the aim to monitor their functional alteration. Furthermore, ability of independent walking may minimize confounding effects due to levels of external assistance and fatigue on outcomes of the tests. Thus, findings of this study further support the reliability and validity of the 10MWT and TUGT to assess and monitor the levels of independence in patients with SCI.

For LEMS, it is normally assessed using the method of manual muscle test. ${ }^{22}$ However, the method has been criticized for its reliability and sensitivity, particularly for the scores above the grade $3 / 5$ level. ${ }^{13}$ Moreover, the method measures the strength of individual key muscles of the lower extremities as designated by the American Spinal Injury Association protocol. These muscles, however, do not include the important contributors for walking such as hip extensor and hip abductor muscles. ${ }^{23}$ Testing on individual muscles also does not account for other contributors to functional ability such as the coactivation of muscle groups, balance control and sensation of individuals. ${ }^{24}$ On the contrary, many studies report that findings of the FTSST are significantly associated with LEMS, balance ability, sensorimotor process and psychological status. ${ }^{12-14}$ However, the investigation was executed in other groups of subjects and the correlation with sensorimotor, balance and psychological status was rather low $(R=0.08-0.28$, $P<0.05$ to $P<0.01) .{ }^{14}$ From the authors' knowledge, there is no existing evidence for the use of FTSST in patients with incomplete SCI. Thus findings of the study primarily support the use of this tool in patients with SCI.

The three functional tools are time-based assessments that the results are sensitive and clearly quantify functional alteration in patients with SCI who walk with and without a walking device. van Hedel et al. ${ }^{18}$ suggest that a sensitive tool is important to detect small changes due to possible positive or negative treatment effects. However, a sensitive tool may encounter a problem of internal consistency and report meaningless alteration. Moreover, results of such tests cannot indicate impairments (affected systems or muscles). Therefore, the tools may be suitable to be used as a screening or monitoring tool, and a thorough system (motor or sensory) assessment, that is, manual muscle test, is still needed. Moreover, a further investigation, such as appropriate effect sizes or cutoff scores to predict ability to wean off a walking device, would enhance the utility of these tools. 


\section{CONCLUSION}

The study evaluated reliability, discriminative ability and concurrent validity of the 10MWT, TUGT and FTSST in independent ambulatory subjects with SCI. The findings support reliability and validity of the tools. Thus, clinical assessments using these tools may clearly quantify functional alteration in ambulatory patients with SCI.

\section{CONFLICT OF INTEREST}

The authors declare no conflict of interest

\section{ACKNOWLEDGEMENTS}

This study was supported by funding from the Thailand Research Fund (TRF), the Improvement of Physical Performance and Quality of Life (IPQ) Research Group and Khon Kaen University, Thailand. We also thank Ian Thomas for his contribution in manuscript preparation.

1 Tang SF, Tuel SM, McKay WB, Dimitrijevic MR. Correlation of motor control in the supine position and assistive device used for ambulation in chronic incomplete spinal cord-injured persons. Am J Phys Med Rehabil 1994; 73: 268-274.

2 National SCl Statistical Center. Annual Statistical Report for the Model SCl Care System. University of Alabama at Birmingham: Birmingham, 2006.

3 Brotherton SS, Krause JS, Nietert PJ. Falls in individuals with incomplete spinal cord injury. Spinal Cord 2007; 45: 37-40.

4 Melis EH, Torres-Moreno R, Barbeau H, Lemaire ED. Analysis of assisted-gait characteristics in persons with incomplete spinal cord injury. Spinal Cord 1999; 37: 430-439.

5 Scivoletto G, Romanelli A, Mariotti A, Marinucci D, Tamburella F, Mammone A et al. Clinical factors that affect walking level and performance in chronic spinal cord lesion patients. Spine (Phila Pa 1976) 2008; 33: 259-264.

6 Bateni H, Maki BE. Assistive devices for balance and mobility: benefits, demands, and adverse consequences. Arch Phys Med Rehabil 2005; 86: 134-145.

7 Koh ES, Williams AJ, Povlsen B. Upper-limb pain in long-term poliomyelitis. QJM 2002; 95: 389-395.

8 Subbarao JV. Walking after spinal cord injury. Goal or wish? West J Med 1991; 154: 612-614.
9 Mahoney JE, Sager MA, Jalaluddin M. Use of an ambulation assistive device predicts functional decline associated with hospitalization. J Gerontol A Biol Sci Med Sci 1999; 54: M83-M88.

10 Jackson AB, Carnel CT, Ditunno JF, Read MS, Boninger ML, Schmeler MR et al. Outcome measures for gait and ambulation in the spinal cord injury population. J Spinal Cord Med 2008; 31: 487-499.

11 Podsiadlo D, Richardson S. The timed 'Up \& Go': a test of basic functional mobility for frail elderly persons. J Am Geriatr Soc 1991; 39: 142-148.

12 Whitney SL, Wrisley DM, Marchetti GF, Gee MA, Redfern MS, Furman JM. Clinical measurement of sit-to-stand performance in people with balance disorders: validity of data for the five-times-sit-to-stand test. Phys Ther 2005; 85: 1034-1045.

13 Eriksrud O, Bohannon RW. Relationship of knee extension force to independence in sitto-stand performance in patients receiving acute rehabilitation. Phys Ther 2003; 83: 544-551.

14 Lord SR, Murray SM, Chapman K, Munro B, Tiedemann A. Sit-to-stand performance depends on sensation, speed, balance, and psychological status in addition to strength in older people. J Gerontol A Biol Sci Med Sci 2002; 57: M539-M543.

15 van Hedel HJ, Wirz M, Dietz V. Assessing walking ability in subjects with spinal cord injury: validity and reliability of 3 walking tests. Arch Phys Med Rehabil 2005; 86: 190-196.

16 Dittuno PL, Ditunno Jr JF. Walking index for spinal cord injury (WISCI II): scale revision. Spinal Cord 2001; 39: 654-656.

17 Read MS, Sisto SA, Ditunno JF. Standardized ambulation assessments following spinal cord injury. Top Spinal Cord Inj Rehabil 2008; 14: 39-60.

18 van Hedel HJ, Wirz M, Dietz V. Standardized assessment of walking capacity after spinal cord injury: the European network approach. Neurol Res 2008; 30: 61-73.

19 Ditunno Jr JF, Burns AS, Marino RJ. Neurological and functional capacity outcome measures: essential to spinal cord injury clinical trials. J Rehabil Res Dev 2005; 42 : 35-41.

20 Finch E, Brooks D, Stratford P, Mayo N. Physical rehabilitation outcome measures: a guide to enhanced clinical decision making, 2nd edn BC Decker: Hamilton, 2002.

21 Janssen WG, Bussmann HB, Stam HJ. Determinants of the sit-to-stand movement: a review. Phys Ther 2002; 82: 866-879.

22 Maynard Jr FM, Bracken MB, Creasey G, Ditunno Jr JF, Donovan WH, Ducker TB et al. International standards for neurological and functional classification of spinal cord injury. American Spinal Injury Association. Spinal Cord 1997; 35: 266-274.

$23 \mathrm{Kim} \mathrm{CM}$, Eng JJ, Whittaker MW. Level walking and ambulatory capacity in persons with incomplete spinal cord injury: relationship with muscle strength. Spinal Cord 2004; 42: 156-162.

24 Lusardi MM, Pellecchia GL, Schulman M. Functional performance in community living older adults. J Geriatr Phys Ther 2003; 26: 14-22. 